\title{
Antibiotic stewardship at St Paul's Hospital
}

\author{
Glen Brown PharmD FCSHP BCPS
}

A ntibiotic stewardship has been receiving increasing attention since the consequences of widespread antibiotic use became apparent. For at least the past 15 years, the medical and pharmacy staffs of St Paul's Hospital have realized the importance of proper antibiotic use, and have established policies, procedures and review bodies in an attempt to optimize antibiotic use. The main driving force for these developments has been the realization of the hospital's potential excessive financial costs if antibiotics were used inappropriately. Many of the strategies implemented to confine antibiotic use were initiated as cost minimization efforts; however, efforts to minimize antibiotic use also limited the exposure of the hospital's intrinsic microbiological flora to excessive antibiotic use. The impact of control measures on the prevention or minimization of resistant flora development cannot be accurately measured because a valid monitoring program of antimicrobial resistance was not in place before or after implementation of the control measures. Anecdotally, St Paul's Hospital has not yet experienced outbreaks of resistant organisms similar to those reported in other Canadian and North American hospitals. The role of control measures taken to prevent antimicrobial resistance outbreaks cannot be verified, but control measures should not have been detrimental to minimizing hospital flora exposure to antibiotics.

The medical staff established the Antibiotic Subcommittee of the Pharmacy and Therapeutics Committee in the early 1980s. The purpose of the Antibiotic Subcommittee is to develop policies and procedures that ensure optimal availability and use of antibiotics to treat the infectious conditions of St Paul's Hospital patients. The subcommittee is chaired by the chair of the medical microbiology laboratory and comprises an infectious disease consultant, a surgeon, a clinical pharmacologist, a hematologist, an intensivist and a pharmacist. This is a similar composition to what has been recommended (1). The subcommittee has attempted many methods of controlling antibiotic use, similar to many of those suggested by the Society for Healthcare Epidemiology of America (2) (Table 1). The following discussion will focus on several strategies employed at St Paul's Hospital that may have the greatest impact on antibiotic use.

\section{ACTIVITIES OF THE ANTIBIOTIC SUBCOMMITTEE} Formulary restriction: The Antibiotic Subcommittee is the medical committee that makes recommendations on which antibiotics should and should not be available for use within the hospital. This activity has the greatest impact on limiting antibiotic exposure (1). Because the subcommittee has representation from the major disciplines that use antibiotics, particularly infectious diseases, the recommendations for formulary restriction reflect the day-to-day recommendations of influential clinicians.

Antibiotic order form: The subcommittee implemented an antibiotic order form (Figure 1) in the early 1980s to emphasize the importance of careful consideration of what antibiotic to prescribe and when it should be prescribed. To assist the prescriber, an antibiotic sensitivity grid and cost comparison are printed on the back of each form (3). The subcommittee believes that the antibiotic order form continues to contribute to antibiotic control (4); however, it has proven difficult to ensure that the form is completed with the necessary information for retrospective review. Similarly, an ongoing audit process that uses information on the form has not been successfully established.

Restriction of use: The subcommittee has recommended that specific antibiotics be restricted for prescription by certain clinicians or use for specific identifiable indications (Table 2). The pharmacy and therapeutics committee has endorsed the recommendation that clinicians prescribe specific antibiotics only if the clinicians are approved or can demonstrate approved indications for the drug. Drug prescription approval is 
TABLE 1

Methods to implement antibiotic control or restriction policies suggested the Society for Healthcare Epidemiology of America

\begin{tabular}{|c|c|}
\hline Methods & Present \\
\hline \multicolumn{2}{|l|}{ Written hospital guidelines } \\
\hline \multicolumn{2}{|l|}{ National } \\
\hline \multicolumn{2}{|l|}{ Regional (state regulations) } \\
\hline Local & $x$ \\
\hline \multicolumn{2}{|c|}{$\begin{array}{l}\text { Education efforts aimed at changing prescribing practices } \\
\text { of physicians }\end{array}$} \\
\hline Face-to-face presentations & $x$ \\
\hline \multicolumn{2}{|l|}{ Computer interactions } \\
\hline \multicolumn{2}{|l|}{ Pharmacy 'Top 100' expenditures list } \\
\hline \multicolumn{2}{|c|}{$\begin{array}{l}\text { Restriction of hospital formulary through Pharmacy and } \\
\text { Therapeutic Committee }\end{array}$} \\
\hline \multicolumn{2}{|c|}{ Cyclic rotation of antimicrobials within a class } \\
\hline Antibiotic order forms & $x$ \\
\hline Antibiotic stop orders & $x$ \\
\hline Therapeutic use & $x$ \\
\hline Prophylactic use & $x$ \\
\hline Restriction of use & $x$ \\
\hline Removal of specific agents & $x$ \\
\hline \multicolumn{2}{|l|}{ Review of medical record by pharmacists } \\
\hline Decentralized pharmacies & $x$ \\
\hline PharmDs to interact with physicians & $x$ \\
\hline \multicolumn{2}{|l|}{ Usage feedback to physicians } \\
\hline Computerized review & $x$ \\
\hline Group purchasing practices & $x$ \\
\hline Generic substitution & $x$ \\
\hline \multicolumn{2}{|c|}{$\begin{array}{l}\text { Utilization review with guidelines for rational and } \\
\text { appropriate usage }\end{array}$} \\
\hline Antibiotic Utilization Subcommittee & $x$ \\
\hline Multidisciplinary teams & $x$ \\
\hline \multicolumn{2}{|c|}{$\begin{array}{l}\text { Requirement of consultation with infectious diseases } \\
\text { subspecialists for certain antimicrobial choices }\end{array}$} \\
\hline \multicolumn{2}{|l|}{ By telephone approval } \\
\hline By written audit & $x$ \\
\hline Antimicrobial susceptibility reporting & $x$ \\
\hline Reduction of pharmaceutical promotion & \\
\hline
\end{tabular}

X present at St Paul's Hospital, Vancouver, British Columbia

not required before the initial dose of antibiotic is given; therefore, no patient is denied a drug before its approval is obtained. The pharmacy department monitors restricted drugs daily, and contacts any prescriber who has not obtained approval or demonstrated an approved indication. By means of this restrictive policy, the use of antibiotics with wide or unnecessary spectra of activity for inappropriate indications may be reduced (1). The hospital is fortunate to have an infectious diseases service, which is available for consultation for approval of restricted antibiotic use (5). Such approval cannot be obtained by telephone, but rather requires a written consultation from the infectious disease team.

Substitution: To minimize exposure of hospital flora to broad spectrum antibiotics, the subcommittee has approved substitution with alternative antibiotics by the pharmacy department for specific situations. For example, the automatic

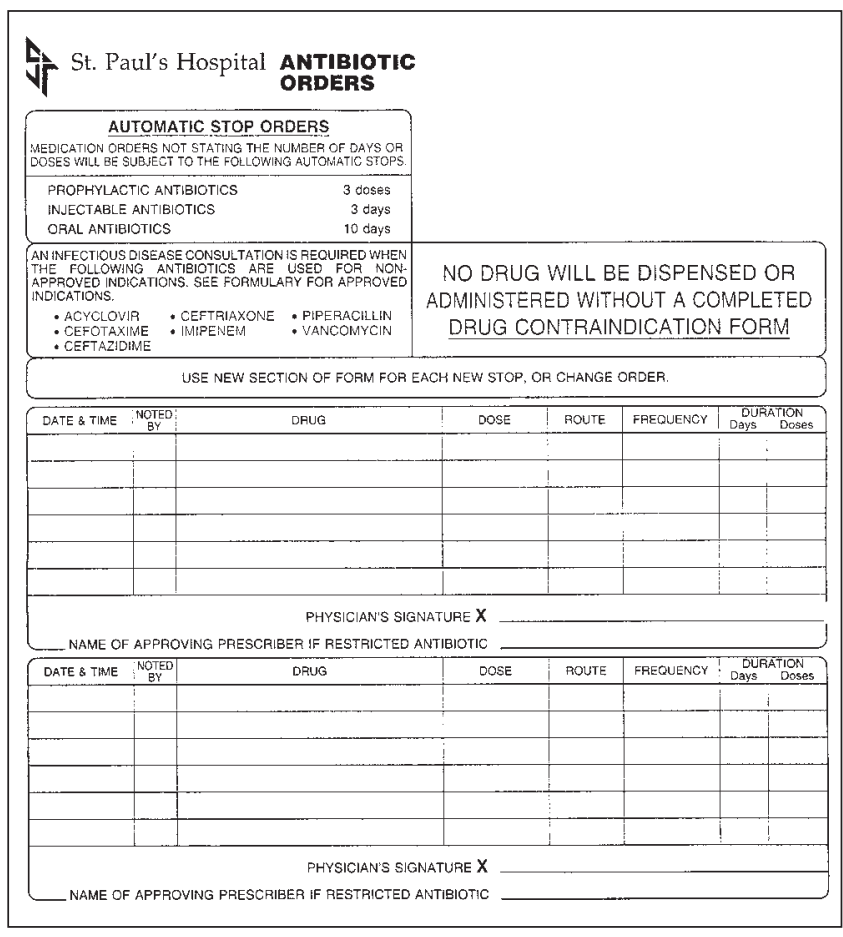

Figure 1) The antibiotic order form of St Paul's Hospital

\section{TABLE 2}

Examples of indications for use of restricted antibiotics approved by the antibiotic subcommittee of the pharmacy and therapeutics committee of St Paul's Hospital

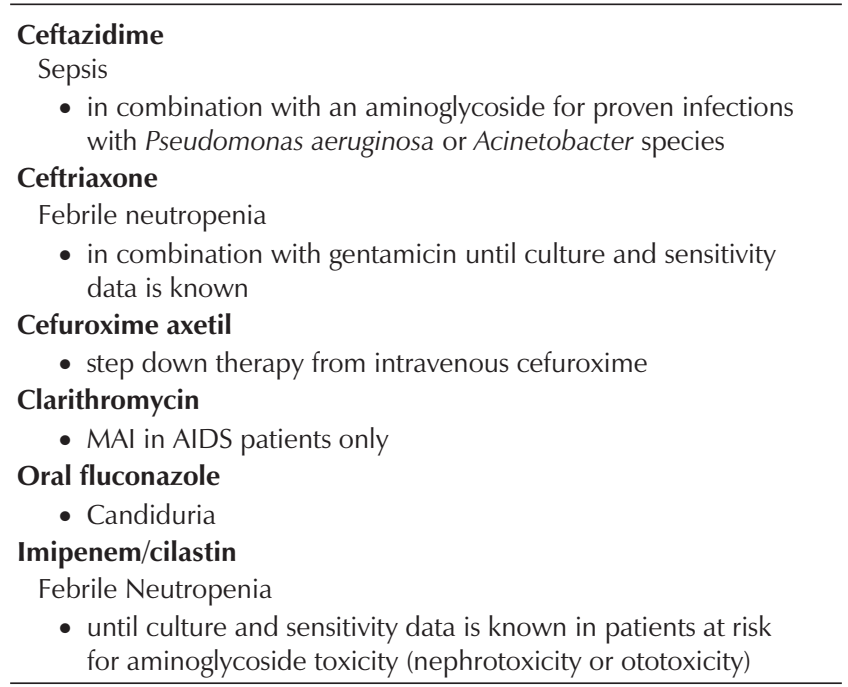

MAl Mycobacterium avium-intracellulare

substitution of a combination of metronidazole plus cefazolin for cefoxitin was shown to be effective and economical at St Paul's Hospital (6). The subcommittee has supported the promotion of alternative therapies with narrower spectra of activity where they are equally effective and more economical, eg, once daily administration of cefazolin with probenecid (versus ceftriaxone only) for the out-patient treatment of cellulitis (7). Exposure of microbes to broad spectrum antibiotics throughout the hospital has been reduced by antibiotic substitutions. Direct pharmacist interaction: The daily efforts of staff pharmacists have largely ensured that subcommittee recommen- 
dations are followed. Each staff pharmacist is responsible for the provision of pharmaceutical care to a varying number of patients in individual treatment areas of the hospital. Pharmacists are responsible for ensuring, in a manner similar to services previously reported (8-12), that patients receive the appropriate antibiotics, based on site of infection, organ function, allergy history and previous antibiotic use. To assist the pharmacists, the pharmacy department prepares a computergenerated report of all in-patients every day, which identifies individual patients receiving restricted drugs and the corresponding dosages. To assist in identifying patients at risk from excessively large antibiotic dosages, a report of all patients with abnormal renal function, indicated by an abnormally high serum creatinine concentration in the day's laboratory results, and the patient's corresponding drug therapy affected by renal dysfunction is prepared for the pharmacist every day. The reports, in conjunction with the pharmacists' direct interaction with the patients and health care team, allow for identification of patients receiving inappropriate antibiotic drugs or dosages. The pharmacists provide a pharmacokinetic dosage service for drugs, including aminoglycosides and vancomycin. Where appropriate, the use of once daily aminoglycoside dosing is recommended in an attempt to minimize inappropriately low antibiotic exposure and its contribution to development of resistance (1). Pharmacists monitor the response to antibiotic

\section{REFERENCES}

1. Duncan RA. Controlling use of antimicrobial agents. Infect Control Hosp Epidemiol 1997;18:260-6.

2. Shlaes DM, Gerding DN, John JF Jr, et al. Society for Healthcare Epidemiology of America and Infectious Diseases Society of America Joint Committee on the Prevention of Antimicrobial Resistance: guidelines for the prevention of antimicrobial resistance in hospitals. Infect Control Hosp Epidemiol 1997;18:275-91.

3. Snyder LL, Clyne KE, Wagner JC. Antibiotic sensitivity and the prescribing information sheet: assisting the prescribing physician. Amer J Infect Control 1990;18:399-404.

4. Kowalsky SF, Echols RM, Peck F Jr. Preprinted order sheet to enhance antibiotic prescribing and surveillance. Am J Hosp Pharm 1982;39:1528-9.

5. John JF Jr, Fishman NO. Programmatic role of the infectious diseases physician in controlling antimicrobial costs in the hospital. Clin Infect Dis 1997;24:471-85.

6. Brown GR, Clarke AM. Therapeutic interchange of cefazolin with metronidazole for cefoxitin. Am J Hosp Pharm 1992;49:1946-50.

7. Brown G, Chamberlain R, Goulding J, Clarke A. Ceftriaxone versus cefazolin with probenecid for severe skin and soft tissue infections. J Emerg Med 1996;14:547-51.

8. Lacy MK, Swartz MA, Eidem LA, Bond JA. Development of a therapy, and make recommendations for change where appropriate. St Paul's Hospital has benefited from work done at Vancouver General Hospital demonstrating the benefits of an intravenous-to-oral step down program, which St Paul's has adopted in a modified form (13). Pharmacists also watch for signs of potential or real toxicity from drug therapy (eg, aminoglycoside toxicity) and intervene where appropriate to minimize the toxicity from drug therapy (14). In the day-to-day activities of pharmacists, the recommendations of the antibiotic subcommittee are put into practice.

\section{SUMMARY}

St Paul's Hospital has attempted to put in place strategies that will minimize the unnecessary or inappropriate use of antibiotics and, thereby, minimize the contribution of such use to the development of resistant organisms. The impact of the strategies implemented at St Paul's Hospital can not be quantified, and it cannot be determined whether the strategies will be adequate to prevent future development of antibiotic resistance. Regardless, strategies continue to be developed and implemented in an attempt to minimize unnecessary antibiotic use within the hospital. The antibiotic subcommittee of St Paul's Hospital continues to meet the challenge to be a leader in the prevention of the emergence of antibiotic-resistant organisms within the hospital's patient population (15).

patient-focused, interdisciplinary antimicrobial management program involving staff pharmacists. Am J Health Syst Pharm 1997;54:1837-41.

9. Klem C, Dasta JF. Efforts of pharmacy to reduce antibiotic resistance. New Horiz 1996;4:377-84.

10. Patel DA, Chang S, Nessim S, Shane R, Morgan MA. Department of pharmacy-initiated program for streamlining empirical antibiotic therapy. Hosp Pharm 1992;27:596-603.

11. Capers CC, Bess DT, Branam AC, et al. Antibiotic surveillance: the results of a clinical pharmacy intervention program. Hosp Pharm 1993;28:206-10.

12. Chawla P, Slayter K. Pharmacist initiated antibiotic streamlining. Can J Hosp Pharm 1996;49:128-9.

13. Frighetto L, Nickoloff D, Marinusen SM, Mamdani FS, Jewesson PJ. Intravenous-to-oral stepdown program: Four years of experience in a large teaching hospital. Ann Pharmacother 1992;26:1447-51.

14. Brown G. Minimizing aminoglycoside toxicity by prescriber notification of prolonged therapy. Hosp Pharm 1995;30:33-6.

15. Goldmann DA, Weinstein RA, Wenzel RP, et al. Strategies to Prevent and Control the Emergence and Spread of Antimicrobial-Resistant Microorganisms in Hospitals: A challenge to hospital leadership. JAMA 1996;275:234-40. 


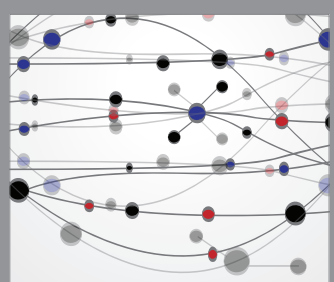

The Scientific World Journal
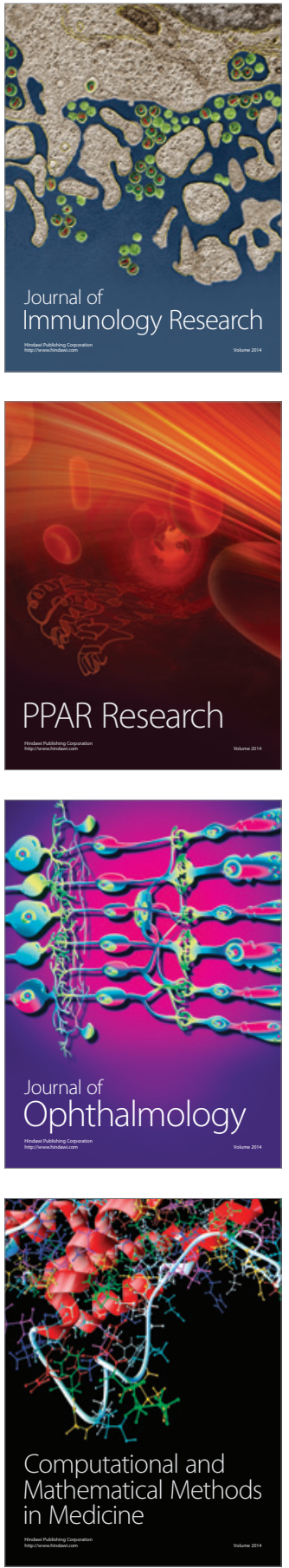

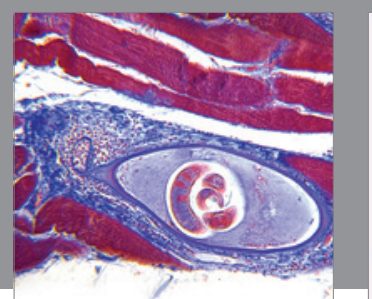

Gastroenterology Research and Practice

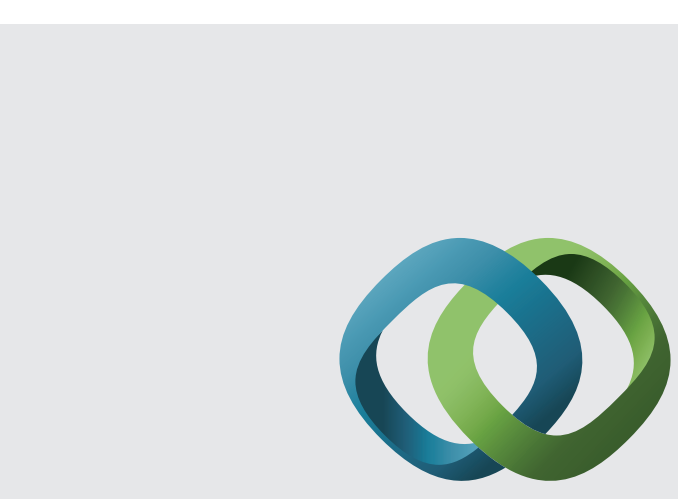

\section{Hindawi}

Submit your manuscripts at

http://www.hindawi.com
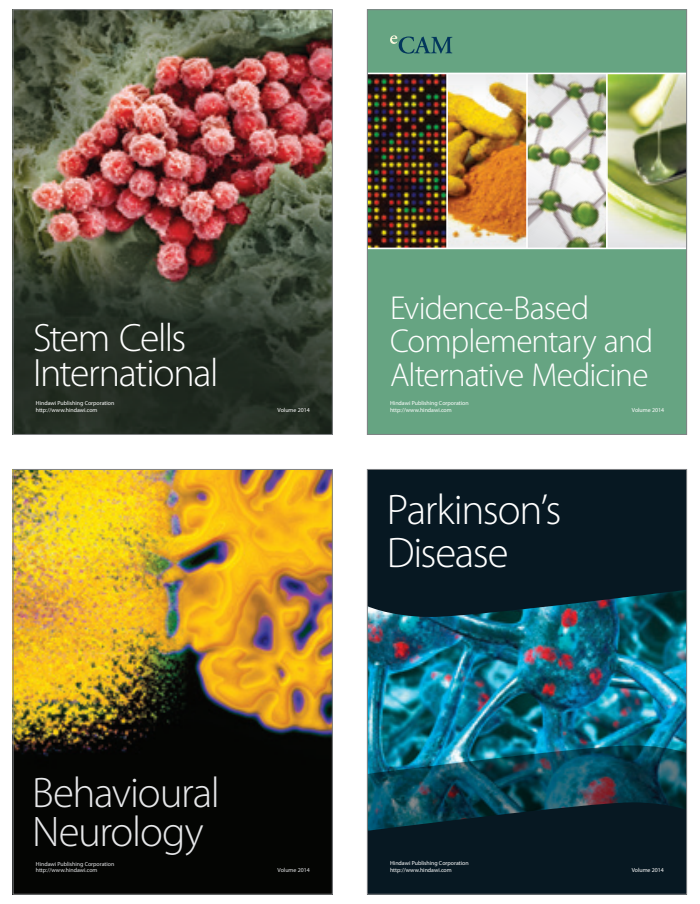
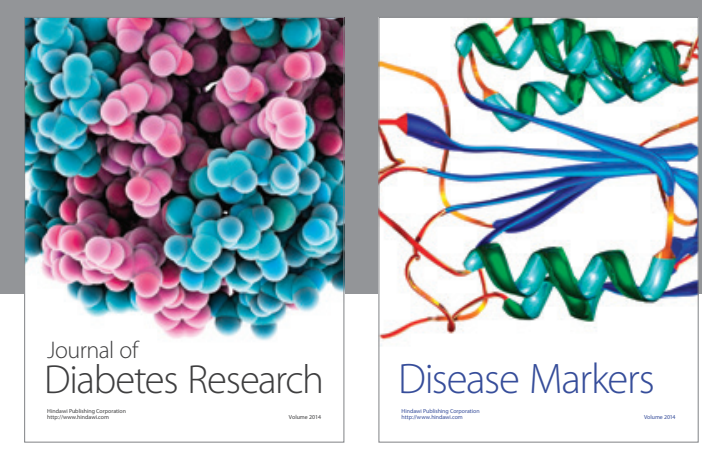

Disease Markers
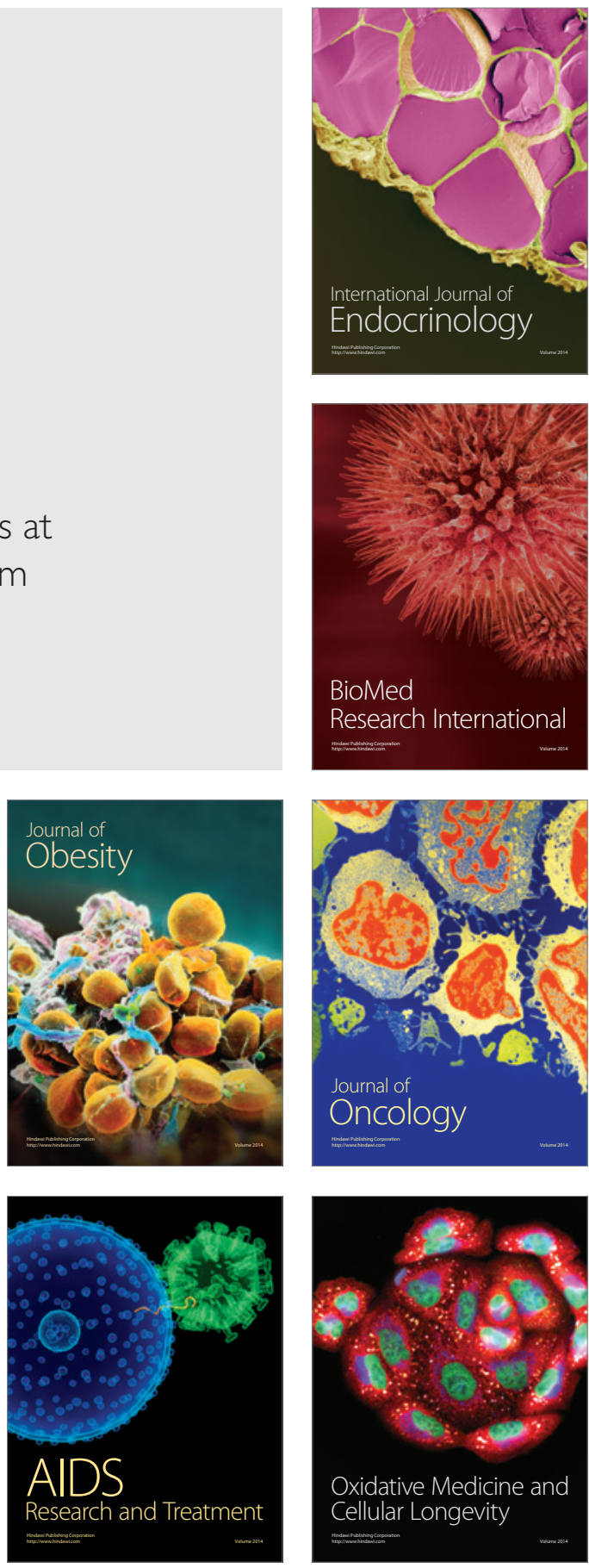